\title{
Context, Anchoring and Dispositional Effects in Evaluating Product Prices
}

\author{
Eitan Elaad, Neta Sayag-Pinto \\ Ariel University Center, Ariel, Israel
}

\begin{abstract}
Evaluation of product prices is to some extent influenced by a diverse set of cognitive heuristics. The context in which the evaluation takes place, internal dispositions and external stimuli influence information processing and judgment formation. In the present field study three groups of factors were applied: (a) product price references (maximum, minimum, or no reference) which were either closely or remotely tied to the actual price of the product; (b) the context in which the products were evaluated (prestigious or less prestigious shopping centers); and (c) internal motivational dispositions which help to generate peoples' expectations and direct their judgments (peoples wealth, education level, and disposition toward quality). Results showed that all factors affected product price estimates. Results were explained by expectations created by heuristics such as anchoring and adjustment and availability. Visitors' different expectations in prestigious centers (quality) and less prestigious centers (bargains) was the most influential factor.
\end{abstract}

Keywords Context, Quality Preference, Anchoring, Adjustment, Decision Making, Price Evaluation, Biases, Heuristics

\section{Introduction}

\subsection{The Fiddler}

Joshua Bell, one of the greatest musicians in the world, was asked by the Washington Post to participate in an experiment and play his violin in a Washington DC subway station. During the morning rush hour, on Friday, January $12^{\text {th }}, 2007$, Bell stood in jeans and a T-shirt, removed his valuable vio lin, handcrafted by Antonio Stradivary, from its case, and started playing one of the greatest pieces of music ever written for a solo violin.

During Bell's 43 minutes of playing, 1097 people passed by. Only seven stopped for a moment to listen and then rushed on to their business. Twenty-seven gave Bell a total of $\$ 32$ and change. The remaining 1070 people hurried by, oblivious to Bell's stellar performance.

When contacted at a later date, several of the passers-by did not remember Bell at all. Others said that they heard the music but they were busy and had other things on their mind. One person said that he saw the violinist but nothing about him struck him as being unusual. Only one young woman recognized Bell and several individuals noticed that it was a pretty good music.

Why didn't people bother to stop and listen? One possible

* Corresponding author:

elaad@netvision.net.il (Eitan Elaad)

Published online at http://journal.sapub.org/ijap

Copyright (C) 2012 Scientific \& Academic Publishing. All Rights Reserved answer corresponds to the state of mind of the passing people. At the rush hour people are driven to arrive at a certain destination (work, meeting, shopping, etc.) on time. Such a drive blocks the processing of situational cues that may distract them from their goal. This may explain why some people did not notice Bell at all. The context provides another explanation for ignoring Bell. Based on the availability heuristic[1] people expect certain events to be more likely in a certain context than others. Street musicians are more common and normative in a subway station than great classical musicians and a street fiddler does not deserve attention.

Internal factors also may motivate people to pay attention to certain events and ignore others. Thus, people who love and understand classical music were expected to pay attention to the unique features of the musician, his performance, the piece of music he played, and the outstanding sound of the violin. Nevertheless, of more than 1000 people that passed Bell by, only one wo man recognized him. Finally, the anchoring and adjustment heuristic played a role in the behavior of the passers by. Anchoring and adjustment[1], refers to the process in which people make an insufficient adjustment from an in itial value (the anchor), resulting in a finaldecision that is biased towards this value. Eply and Gilovich[2] explained that adjustment tends to be insufficient because people stop adjusting once a plausible and satisfactory answer is reached. Poor adjustment is also the result of enhanced accessibility of anchor-consistent information (e.g.[3-4]). The anchor is the amateur street fiddler. Passing people, who find the music of a relatively 
high standard, may adjust their initial expectations wondering whether to stop and listen to the music for a while. However, accessibility of anchor-consistent information such as the site, the musician's apparel, and the behavior of other passing people, reinforces their initial expectations and they pass-by too.

\subsection{Applying Context, Anchoring, and Internal Factors for Products' Evaluation}

Similar factors also operate on peoples decisions in other actual contexts. For example, anchoring and adjustment influence decisions and evaluations people make when judging the proper price of products[5]. Hence, in supermarkets one can find higher-priced products at eye level so that consumers can see them first. This anchor emphasizes the inexpensive prices of other products in the same category. Companies advertise their higher-priced products in strategic locations that are highly visible, allowing consumers to see them, be impressed and buy other products that appear to be a bargain in comparison. Restaurants typically offer a very expensive course in their menu that they seldom sell, merely to tempt diners to spend more for their meals. The expensive samples serve as anchors that affect the internal standards used by diners to evaluate other menu options[6]. While these dishes are rarely selected, other less expensive items are given mo re attention because they are judged to be inexpensive in comparison.

In the most common experimental anchoring paradig ms, people start by rejecting an anchor value and then adjust in a deliberate fashion until they reach a satisfactory answer[7]. The initial anchor is usually provided by an experimenter. In the present study we present high and low reference prices to establish measurable standards. Furthermore, it was suggested that people place greater weight on extreme prices [8]. It is therefore hypothesized that extreme anchors influence judgment of products more than less extreme anchors.

The context in which the evaluation is made may also influence product price evaluations. Several different types of context effects have been identified ([9],[10]) a mong them influences that occur at the point at which judgments are reported using cues from the immediate environment. Kahneman and Miller[11] suggested a norm theory according which people often form standards at the time of judgment on the basis of specific examples that come to mind at that point. Features of the situation as well as the product being evaluated could retrieve such available examples[6].

In addition to the context, internal motivational factors generate peoples' expectations and direct their judgments. In a price evaluation task factors such as the wealth of the evaluators, their education level, and their disposition toward quality, may influence evaluators' decisions. The interaction between the external context and such internal standards helps to determine the result of the evaluation.

\subsection{The Present Study}

In a previous study[12], two factors were applied to product pricing estimates: the price reference of the product (maximu m, minimum, or no price reference) and the prestige of the shopping center (prestigious, less prestigious) in which the study was conducted. Elaad et al. found that perceived prestige influenced product pricing. It was suggested that people in the more-prestigious centers are less interested in product cost than visitors to less prestigious centers, and therefore were less responsive to the reference price. In the less prestigious shopping centers, people look for bargains and emphasize the product price. As a result, they tend to underestimate product prices. In the Elaad et al. study, people in the prestigious centers attributed the highest price to products in the no-anchor condition. This result moderated the expected anchor effect. The reas on may be the actual low product price (30 NIS - about \$8) and the fact that the anchors were closer to the actual price. It seems that people in prestigious shopping centers judged product prices independently of their reference prices.

To overcome these difficulties it was decided to replicate the study of Elaad et al.[12] using more expensive products and more extreme deviations from actual product prices. It was further decided to conduct the study in four prestigious and four less prestigious centers, instead of two centers of each type used in the Elaad et al. study. Finally, unlike Elaad et al., direct questions were posed to participants about their tendency to prefer quality over price or vice versa. Further questions were designed to learn about other participants' dispositions which may influence the price evaluation task.

Three factors were manipulated in the present study. We varied the context by selecting prestigious (elegant shops, high prices) and less prestigious (no elegance, low prices) shopping centers. It was hypothesized that as quality products are more available in prestigious shopping centers than in less prestigious centers, participants in the prestigious centers will attribute quality to the products and will evaluate them higher than in the less prestigious centers. We varied the reference prices by presenting prices that displayed extreme and less extreme deviations fro $m$ the actual product price, and we varied the direction of the anchor by presenting reference prices that were either higher or lower than the actual price of the product. It was hypothesized that the combination of a prestigious shopping center and an anchor price reference higher than the actual product price would most effectively make people overestimate product price. The comb ination of extre mely low prices in less prestigious centers would make participants underestimate the price of the product. When participants face inconsistent evidence (e.g., extremely low anchor in a prestigious center), anchoring effects are expected to be moderated.

\section{Method}

\subsection{Participants}

288 participants were randomly selected from eight (four 
prestigious and four less prestigious) shopping centers in Is rael. Prestige was determined according to the elegance of the shops and the prices of products. Participants were asked to estimate product prices. One-half of the responses were collected from participants in prestigious centers $(39.6 \%$ males and $60.4 \%$ females; Mean age $=37.6$ years, $\mathrm{SD}=14.9$ ) and one-half were collected from participants in less prestigious centers $(52.8 \%$ males, $47.2 \%$ females; Mean age $=34.1$ years, $\mathrm{SD}=13.8)$. Using one-way ANOVA, a significant age difference was obtained, $F_{(1,286)}=4.2, p<.05$, $d=.24$. We used Cohen's $d$ as the effect size index, where $d \mathrm{~s}$ of $0.20,0.50$, and 0.80 were used as thresholds of small, med ium, and large effects, respectively[13]. The small effect size compromises the age effect importance. A $\chi^{2}$ procedure was employed to examine the different frequencies of males and females in the two shopping center types. No significant differences were found, neither for males $\chi_{(1)}^{2}=2.71(n s)$ nor for females $\chi_{(1)}^{2}=2.33(n s)$.

\subsection{Procedure}

Participants were approached by two female researchers and were asked to evaluate product prices whose actual sales price was NIS 90 (about \$24). Participants were presented with three items (a decorated box, a serving dish, and an album). Similar to other anchoring studies [14], either, high, low, or no reference price preceded the presentation of each product. Participants assigned to the narrow reference price range condition, were informed: "The price should not exceed NIS 150" (high reference) or "The price should be no less than NIS 30" (low reference). The respective high and low reference prices for the broad reference price range condition were NIS 170, and NIS 10 . The presentation order of items and reference prices was counterbalanced across participants in each anchor range condition and in each shopping center.

Furthermore, participants were asked several personal questions about their age, gender, and education. Educational attainment was defined as one of the following four levels: (1) elementary school education; (2) high school education; (3) partial post-secondary education (e.g., undergraduate students); (4) academic degree. After responding to these questions participants completed a questionnaire. The first item asked participants to evaluate the prestige of the shopping center they were visiting. The evaluation was made on a 10-point scale ranging from very low (1) to very prestigious (10). The next item concerned participants' income ("What is the income group you belong in?"). Possible answers were: (1) low income group; (2) moderately low income group; (3) moderately high income group; (4) high income group. In the final item, participants described their buying preferences by expressing agreement with one of the following statements: (1) I am looking for a bargain irrespective of product quality; (2) I prefer inexpensive products but also consider the quality of the product; (3) I prefer quality products but also consider the price of the product; (4) I am looking for product quality irrespective of price.

\section{Results}

\subsection{Prestige Level Check}

After estimating the product prices, participants evaluated the prestige of the shopping center they were visiting. Means and standard deviations were $\mathrm{M}=8.47(\mathrm{SD}=1.25)$, and $\mathrm{M}=$ $3.12(\mathrm{SD}=1.79)$, respectively for prestigious and less prestigious centers. A one-way ANOVA was performed on the prestige ratings, yielding a significant effect, $F_{(1,257)}=$ $772.2, p<.001, d=3.47$. Cohen's d was used to estimate the effect size. Note that only 129 participants from each prestige group answered this question. We conclude that participants were aware of the status of the shopping center they visited.

\subsection{Dispositional Factors}

Another factor that may affect price evaluation is participants' income level. It was found that reported income was significantly correlated with price evaluation, $r_{(279)}=.12$, $p<.05$, which implies that participants with higher incomes assigned higher prices to products regardless of reference price and shopping center prestige. The means and standard deviations computed for the income of people visiting prestigious and less prestigious shopping centers were compared $(\mathrm{M}=2.70, \mathrm{SD}=.70, \mathrm{~N}=142$, and $\mathrm{M}=2.23, \mathrm{SD}$ $=.70, \mathrm{~N}=137$, respectively). Using $t$-test for independent samples, and Cohen's d for effect size, the difference was significant, $t_{(277)}=5.7, p<.001, d=.67$, indicating that visitors of prestigious shopping centers reported higher income levels than visitors in less prestigious centers. A second internal anchoring factor is participants' education. Again, a significant correlation with price evaluation was obtained, $r_{(288)}=.17, p<.005$. We compared participants' education levels in the two center types and found that visitors in the prestigious centers reported higher levels of educational attainment $(\mathrm{M}=3.27, \mathrm{SD}=.88, \mathrm{~N}=144)$ than visitors in the less prestigious centers $(\mathrm{M}=2.72, \mathrm{SD}=.99, \mathrm{~N}$ $=144)$. The difference was significant $\left(t_{(286)}=4.96, p<.001\right.$, $d=.63$ ).

It was further hypothesized that people who prefer quality over price would assign higher prices to the presented products. The correlation was positive but not significant, $r$ $(273)=.07,(n s)$. The reported preferences of visitors in the prestigious and less prestigious centers were compared $(\mathrm{M}=$ $2.79, \mathrm{SD}=.62, \mathrm{~N}=141$, and $\mathrm{M}=2.58, \mathrm{SD}=.79, \mathrm{~N}=132$, respectively), and a significant difference was revealed, $t_{(271)}$ $=2.38, \mathrm{p}<.05, d=.30$. In summary, results show that visitors to prestigious shopping centers have higher income levels than visitors in less prestigious centers, are more educated, and tend to prefer quality over price.

Finally, correlations between the three dispositions, across reference anchors and shopping centers, were computed. 
Peoples preferences and reported income levels were significantly correlated, $r_{(272)}=.35, \mathrm{p}<.001$. That is, people with higher incomes prefer quality over prices. Peoples preference was also significantly correlated with education, $r$ ${ }_{(273)}=.12, p<.05$, indicating that people with higher levels of educational attainment prefer quality over price. The correlation between reported income and education levels was also significant, $\mathrm{r}_{(279)}=.12, p<.05$, imply ing that higher education is related to higher income.

\subsection{Context and Anchoring Effects}

A $2 \times 2 \times 3$ ANOVA with two between-subject factors, Prestige (prestigious and less prestigious centers), Range (narrow and broad references), and one within-subject factor, Anchor (high, low, and no anchor), was performed on participants' price estimates. A significant Prestige effect, $F$ $(1,284)=28.2, p<.001, \eta_{\mathrm{p}}^{2}=.09$, indicates that participants in prestigious centers assigned higher price estimates to products compared to visitors in less prestigious centers (M $=91.8, \mathrm{SD}=34.4 ; \mathrm{M}=73.4, \mathrm{SD}=23.4$, respectively). $\mathrm{A}$ significant Anchor effect, $\varepsilon=.914, F_{(1.83,519.1)}=45.2, p$ $<.001, \eta_{\mathrm{p}}^{2}=.14$, indicates that high anchor yielded the highest price estimates and the low anchor generated the lowest price estimates (see Table 1). No significant main effect for Range was found. A significant, $F_{(1.83,519.1)}=4.4, p$ $<.05, \eta_{\mathrm{p}}^{2}=.02$, Prestige $\times$ Anchor interaction effect suggests that the gradual decline in estimated product prices as a function of the type of anchor used, appears more strongly in the less prestigious centers and less so in prestigious centers (Table 1). Finally, a significant Anchor $\times$ Range, $F_{(1.83,519.1)}=$ $3.2, p<.05, \eta_{\mathrm{p}}^{2}=.01$, interaction effect was obtained. The interaction suggests that the gradual decline of prices from the high anchor, through the no-anchor, to the low anchor is more pronounced in the broad range reference condition than in the narrow reference range condition (Table 1). No other significant interaction effects were found.

\subsection{Regression Analysis}

As the three dispositions (people preference, education, and income) were found to be closely interrelated and are also related to the prestige of the shopping center, it is possible that they mediate the price estimates.

Table 1. Means (and SDs) of Evaluated Prices to Products in Prestigious and Less Prestigious Shopping Centers in two Reference Range Conditions and Three Anchor Types

\begin{tabular}{|c|c|c|c|c|c|c|c|c|}
\hline \multirow{2}{*}{$\begin{array}{l}\text { Reference range } \\
\text { Anchor type }\end{array}$} & \multirow[b]{2}{*}{ High } & \multicolumn{3}{|c|}{ Narrow range } & \multicolumn{2}{|c|}{ Broad range } & \multicolumn{2}{|c|}{ Across range } \\
\hline & & No & Low & High & No & Low & High & No \\
\hline
\end{tabular}

\section{Shopping centers}

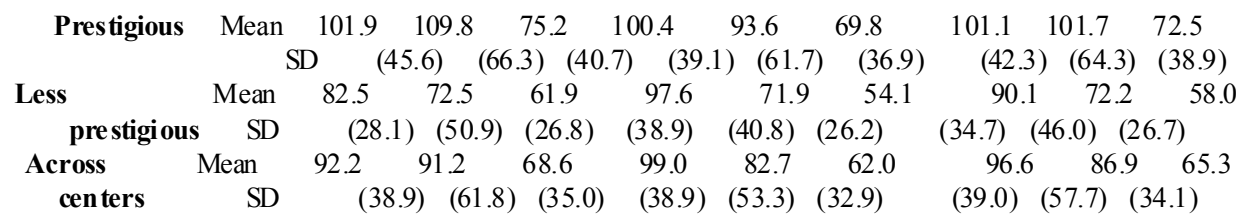

Table 2. Standardized Regression Coefficients of Personal Dispositions and the Centers' Prestige Predicting Price Evaluations

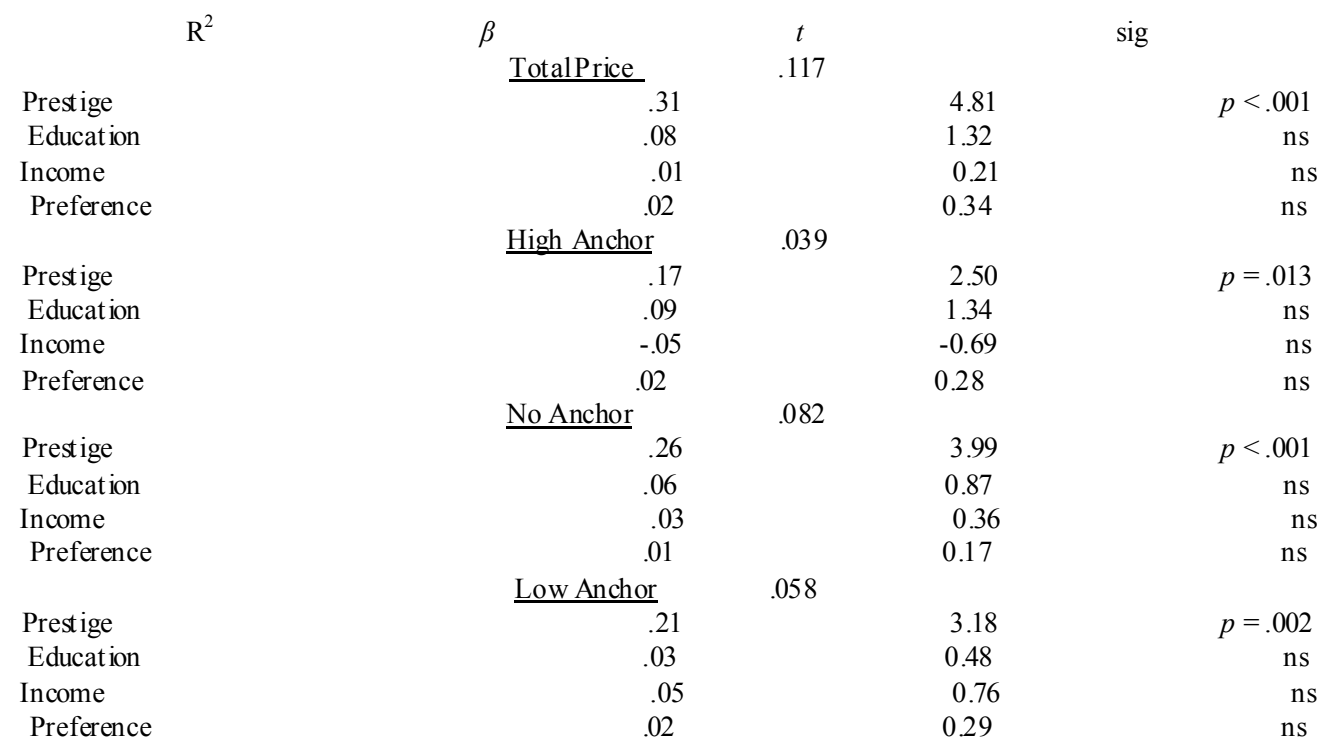


To examine the contribution of the three dispositions and the contexts' prestige to predicting the various price estimates (high, no, and low anchored prices) as well as the total price (the mean total price across within-subjects anchoring conditions), four multiple regressions were conducted, in which dispositions and prestige were entered as the independent variables and the different estimated prices were the dependent variables (see Table 2). The regression analys is showed that the context was the best price predictor and significantly predicted all the prices, whereas the three dispositions added very little to the estimated prices.

\section{Discussion}

\subsection{Context}

Expectations about the price of a product can be generated by context in formation such as the prestige of the shopping center in which people make their purchases. The status of the shopping centers, in which the present study took place, was manipulated and was easily perceived by participants who clearly distinguished between prestigious and less prestigious centers. Prestige was determined by the elegance of the shops, by the quality and high prices of the products and most of all by the behavior of other people. People go to prestigious centers to enjoy themselves, to meet friends, to be seen, and to purchase quality products. They are relatively calm and relaxed. In less prestigious centers people rush fro m one shop to another to find the best price: They are loud and often haggle over the prices offered to them. It emerged that the prestige of the site was the most influential factor in determining the evaluated product price. The context effect may be explained by the availability heuristic that as sociate between prestigious shopping centers and quality. Quality products are more common and available in prestigious centers than in less prestigious centers and therefore more salient. When asked about a product available on site, the idea that the product is of good quality comes to mind more readily than that it is of poor quality[15-16]. As a consequence people tend to overestimate its price. The opposite is true for less prestigious centers. Here, retrieval from memory of inexpensive articles is easier than retrieval of quality articles, and an underestimation of the product price is very likely.

\subsection{Inter nal-Motivational Dispositions}

Internal-motivational dispositions such as education, income, and purchase preferences also play a role in creating expectations about the price of a product. It is evident that people in prestigious shopping centers seek quality more than people who visit less prestigious malls. Therefore, when asked to estimate the price of a product they assume it is of good quality and their estimate is higher than the product's actual price. Furthermore, they reported higher income than visitors in less prestigious centers and therefore are less interested in the cost of the product and are less responsive to reference prices. It has been previous ly suggested that a mo re effective factor in prestigious centers is the time entailed in producing the product rather than its price[17]. In less prestigious shopping centers, people with lower incomes seek bargains and tend to underestimate the product price. Since cost is the most important product feature, reference prices anchored participants' price estimates more effectively than the reference prices in the more prestigious centers.

\subsection{Anchoring and Adjus tment}

The standard people use to evaluate products can also be manipulated by principles of anchoring and adjustment. Such manipulations are often applied through information provided to the evaluator by another person, which serves as an anchor. People tend to reject the anchor and adjust their evaluation in a deliberated fashion until they are satis fied[7]. In the present study maximum and minimum reference prices were used for this purpose and participants were asked to adjust their evaluation in a given direction. Most of the participants complied but some participants in the prestigious shopping centers gave evaluations higher than the maximum reference price. Using maximum and minimum prices is not a common procedure in anchoring and adjustment studies but results indicated that the adjustment was still not sufficient and the evaluated prices stayed close to the anchors. Thus, the high anchor generated higher price evaluations than the low anchor. The results are in line with previous reports[12].

Furthermore, it was hypothesized that participants would place greater weight on a wider range of prices when anchoring their price judgments. The present results suggest that the price range was the least effective anchor. There was no significant main effect and the effect of the range factor was limited to a more pronounced decline of estimated prices from the high anchor, through the no-anchor, to the low anchor in the broad reference range condition than in the narrow reference range condition. Possibly, the broad range of reference price was not sufficiently broad to distinguish it fro $m$ the narro $w$ reference range.

\subsection{Limitations of the Present Study}

The present study is a field study. In this respect, it is inevitable that shopping centers that specialize in elegance, quality, and high prices attract the attention of wealthy, educated, and quality-oriented people, and discourage poor and price-oriented people. These differences in visitors' internal dispositions may have contaminated anchor-cons istent information. More specifically, the higher price estimates in prestigious centers can also be accounted for by participants' higher levels of education, and income, and the desire for quality. To control for such mediating effects we performed a regression analysis. Results showed that anchoring expectations were not predicted by personal dispositions. This is additional evidence of the robust influence of context in creating expectations, as previously 
demonstrated by passer-bys' indifference to Joshua Bell's performance in a subway station, and further revealed in the present price estimation study. The comparison of the price evaluation situation with the street fiddler example demonstrates that the described biases can be generalized and applied to a variety of actual situations.

\subsection{Conclusions and Recommendations}

On a more practical perspective of people behavior, individuals who try to estimate product prices or evaluate the value of objects, are advised to consider their expectations and how they may be manipulated by others using availability and anchoring principles. They should consider the potential impact of the availability heuristic rooted in the context they find themselves in, as well as their dispositions toward quality preferences, their educational and economic status, and the reference prices offered to them as anchors. Finally, people should also be aware of the limited power of the adjustment they may consciously make in their attempt to override these effects. Taking all these factors into account may help them make more informed and rational decisions.

\section{REFERENCES}

[1] Amos Tversky, Daniel Kahneman, "Judgment under uncertainty: Heuristics and biases", Science, 185, pp. 1124-1131, 1974.

[2] Nicholas Eply, Thomas Gilovich, "The anchoring-and-adjustment heuristic: Why the adjustments are insufficient", Psychological Science, 17, pp. 311-318, 2006.

[3] Thomas Mussweiler, Fritz Strack, "Hypothesis-consistent testing and semantic priming in the anchoring paradigm: A selective accessibility model", Journal of Experimental Social Psychology, 35, pp. 136-164. 1999.

[4] Thomas Mussweiler, Fritz Strack, "The semantics of anchoring", Organizational Behavior and Human Processes, 86, pp. 234-255, 2001.

[5] Richard A. Briesch, Lakshman Krishnaqmurthi, Tridib Mazumdar, Sevilimedu, P. Raj, "A comparative analysis of reference price models", Journal of Consumer Research, 24, pp. 202-214, 1997.
[6] Rashmi Adaval, Kent B. Monroe, "Automatic construction and use of contextual information for product and price evaluations", Journal of Consumer Research, 28, pp. 572-588, 2002.

[7] Nicholas Eply, Thomas Gilovich, "When effortful thinking influences judgmental anchoring: Differential effects of forewarning and incentives on self- generated and externally provided anchors. Journal of Behavioral Decision Making, 18, pp. 199-212, 2005.

[8] Ronald W. Niedrich, Subash Sharma, Douglas H.Wedell, "Referece price and price perceptions: A comparison of alternative models. Journal of Consumer Research, 28, pp. 339-354, 2001

[9] John G. Lynch Jr, Chakravati Dipankar, Mitra Anusree, "Contrast effects in consumer judgments: Changes in mental representations or in the anchoring of rating scales?", Journal of Consumer Research, 18, pp. 284-297, 1991.

[10] E. Troy Higgins, Liora Lurie, L. "Context, categorization, and memory: The "change-of-standard" effect", Cognitive Psychology, 15, 525-547, 1983.

[11] Daniel Kahneman, Dale T. Miller, "Norm theory: Comparing reality to its Alternatives", Psychological Review, 93, pp. 136-153, 1986

[12] Eitan Elaad, Neta Sayag, Alia Ezer, "Effects of anchoring and adjustment in the evaluation of product pricing", Psychological Reports, 107, pp. 58-60, 2010.

[13] Jacob Cohen, "Statistical power analysis for the behavioral sciences", Hillsdale, NJ: Lawrence Erlbaum, 1988.

[14] Michael A. Kamins, Xavier Dreze, Valerie S. Folkes, "Effects of seller-supplied prices on buyers' product evaluations: Reference prices in an internet auction context", Journal of Consumer Reseapp. 622-628, 2004.

[15] Susan T. Fiske, Shelley E. Taylor, "Social Cognition", $2^{\text {nd }}$ ed., New York: McGraw-Hill, 1991.

[16] Amos Tversky, Daniel Kahneman, (1973). ""Availability": A heuristic for judging frequency and probable cause", Cognitive Psychology, 5, pp. 207-232. 1973.

[17] Justin Kruger, Derrick Wirtz, Leaf Van Boven, William T. Altermatt, "The effort Heuristic" Journal of Experimental Social Psychology, 40, pp. 91-98, 2004. 